\title{
PROPORCIONALIDADE NA JURISPRUDÊNCIA CONSTITUCIONAL CANADENSE E GERMÂNICA*
}

\section{Dieter Grimm}

Ex-juiz da Corte Constitucional Federal da Alemanha. Professor de Direito da Universidade Humboldt de Berlim, Reitor do Instituto de Estudos Avançados Wissenschaftskolleg zu Berlin.

\begin{abstract}
Resumo: A Corte Constitucional Alemã (1951) começou a transferir o teste de proporcionalidade para a lei constitucional e o aplicou às leis que limitavam direitos fundamentais. 0 princípio da proporcionalidade parece resultar do texto da Constituição, mais remotamente na Alemanha do que no Canadá. Basicamente ambas as jurisdições seguem o mesmo caminho quando aplicam o teste da proporcionalidade. Uma vez que ele requer uma comparação entre meios e fins, ambas as Cortes começam declarando o propósito da lei sob revisão. A terceira fase do teste é, em ambos os países, uma análise de custo-benefício, que requer um sopesamento entre os interesses dos direitos fundamentais e o benefício cujo interesse o direito é limitado. A fase 3 do teste de proporcionalidade dá eficácia plena aos direitos fundamentais. As duas fases anteriores podem revelar a falha da lei ao alcançar seu objetivo. 0 perigo de decisões políticas pode ser evitado determinando-se cuidadosamente sobre o que é avaliado quando se chega ao sopesamento. Cada fase requer uma certa avaliação, e a próxima fase pode ser avaliada somente se a lei que é desafiada não falhe na fase anterior. Deve ser evitada a confusão de fases, que pode gerar um resultado arbitrário e menos previsível.
\end{abstract}

Palavras-chave: Proporcionalidade. Teste. Jurisprudência. Canadá. Alemanha.

Sumário: 1 Oakes e o modelo germânico - 2 Desenvolvimento da proporcionalidade na Alemanha 3 Diferentes abordagens: o objetivo - 4 Mais diferenças: fase 2 - 5 Uma grande lacuna: equilíbrio 6 Preocupações justificadas? - Referências

\section{Oakes e 0 modelo germânico}

A Canadian Charter of Rights and Freedoms ${ }^{1}$ está em vigor há não mais que quatro anos, quando a Corte Suprema finalmente encontrou a resposta para a

* Originalmente publicado no University of Toronto Law Journal, Volume 57, Number 2, 383-397, Spring 2007. Disponivel em: <https://muse.jhu.edu/journals/university_of_toronto_law_journal/v057/57.2grimm.html>. Traduzido por Cristiane De Marchi, Mestranda em Direito pela Pontifícia Universidade Católica do Rio Grande do Sul - PUC/RS. Especialista em Direito Tributário pela Fundação Getúlio Vargas e em Gestão de Tributos e Planejamento Tributário Estratégico pela Pontifícia Universidade Católica do Rio Grande do Sul - PUC/RS. Advogada. Bolsista da CAPES.

1 Carta dos Direitos e Liberdades Canadenses, parte I do Ato Constitucional, 1982, conforme o Calendário B do Ato Canadense 1982, Reino Unido, capítulo 11 (Carta). 
questão de como interpretar a cláusula de limitação no s. 1. A resposta dada em R. v. Oakes $^{2}$ foi, em resumo: legalidade e proporcionalidade. ${ }^{3}$

O primeiro componente, legalidade, teve uma base clara no texto do s. 1 ("prescrito por lei”), enquanto o segundo, proporcionalidade, parece ser uma interpretação genuína das palavras 'limites razoáveis [...] como pode ser justificado comprovadamente em uma sociedade livre e democrática".

Em sua opinião, o Chief Justice ${ }^{4}$ Dickson ofereceu uma estrutura conceitual completa para o requisito da proporcionalidade, embora a maioria das inovações doutrinárias se desenvolva ao longo do tempo até encontrar sua forma final. Essa estrutura, chamada de teste de Oakes, tem sido aplicada pela Corte Suprema há duas décadas, embora seus componentes tenham sido esclarecidos ou modificados mais tarde, e seu rigor original tenha sido mitigado em certos tipos de casos. ${ }^{5}$ Justice lacobucci ${ }^{6}$ teve uma parte importante nesse desenvolvimento. ${ }^{7}$

Saber se o Chief Justice Dickson, ao escrever sua opinião no caso Oakes, foi ajudado por exemplos estrangeiros ou desenvolveu o teste completamente por si mesmo, permanece em aberto. É verdade que algumas dessas linguagens em Oakes assemelham-se à opinião da Suprema Corte Americana em Central Hudson Gas \& Eletric Corp. v Public Service Commission de New York, ${ }^{8}$ um caso de discurso comercial decidido em 1980. Mas a Central Hudson não foi nem uma decisão de estabelecimento de novas tendências, que ganhou muita influência fora dos problemas do discurso comercial, nem é seu teste de proporcionalidade tão elaborado e completo quanto o sugerido pelo Chief Justice Dickson. Embora a Suprema Corte Americana frequentemente recorra ao equilíbrio, não foi desenvolvido o conceito de proporcionalidade, muito menos o transformou em um teste doutrinário comparável ao teste de Oakes. Contudo, em um número de recentes

[1986] 1 S.C.R.103 [Oakes].

Veja: Lorraine Weinrib, 'Canada's Charter of Rights: Paradigm Lost?' (2002) 6 Rev. Const. Stud. 119 [Weinrib, 'Paradigm Lost?'].

4 Chief Justice: Presidente da Suprema Corte Canadense, que é composta por todos os principais ministros e chefes dos juízes associados dos tribunais superiores no Canadá (nove integrantes). O denominado 'Chefe de Justiça' é empossado como membro do Queen's Privy Council for Canada antes de tomar o juramento de posse.

5 Ibid. Veja também, Sujit Choudhry, 'So What Is the Real Legacy of Oakes? Two decades of Proportionality Analysis under the Canadian Charter's Section 1' (2006) 34 Sup. Ct. L. Rev. (2d) 501 [Choudhry, 'So What is the Real Legacy of Oakes?'].

6 Justice Frank lacobucci (nascido em 29 de junho de 1937) foi um puisne Justice (termo usado quase exclusivamente na common law), para designar o magistrado que compõe a Suprema Corte Canadense.

7 Veja, por exemplo, RJR MacDonald Inc. v. Canada, [1995] 3 S.C.R. 199 at paras. 179-192; Vriend v. Alberta, [1998] 1 S.C.R. 493 at paras.108-end; M. v. H., [1999] 2 S.C.R. 3 at paras. 75-end; Delisle v. Canada, [1999] 2 S.C.R. 989; Figueroa v. Canada (Attorney General), [2003] 1 S.C.R. 912.

8 Empresa Central de Gás e Eletricidade de Hudson versus Comissão de Serviço Público de Nova York. 447 U.S. 557 (1980) [Central Hudson]. 
decisões, o Justice Breyer ${ }^{9}$ mostrou um interesse em introduzir uma análise da proporcionalidade no Direito Constitucional dos EUA, ${ }^{10}$ sem contudo convencer a maioria de seus colegas magistrados.

Há, contudo, uma jurisdição que poderia ter servido como um modelo nomeadamente germânico. ${ }^{11}$ Aqui, o teste de proporcionalidade tem sido aplicado desde o final dos anos 50, sempre que a Corte Constitucional tinha que revisar leis que limitam os direitos fundamentais, ou decisões administrativas e judiciais que aplicam tais leis. Da Alemanha, o princípio da proporcionalidade espalhou-se para a maioria dos outros países europeus com um sistema de revisão judicial, e para um número de jurisdições fora da Europa. Da mesma forma, ele é usado na Corte de Direitos Humanos Europeia e na Corte de Justiça Europeia. Os testes de proporcionalidade alemão e canadense diferem levemente na sua terminologia, mas parecem mais ou menos semelhantes na substância. Contudo, uma comparação mais próxima revela algumas diferenças significativas em como os testes são aplicados. Talvez a diferença mais conspícua seja que, no Canadá, a maioria das leis que falham para conhecer o teste o fazem na fase 2 , de forma que não muito é deixado para a fase 3 , enquanto que, na Alemanha, a fase 3 se tornou a etapa mais decisiva no teste da proporcionalidade. Um exame da diferença pode lançar alguma luz nas forças e fraquezas das duas abordagens.

\section{Desenvolvimento da proporcionalidade na Alemanha}

O teste de proporcionalidade é mais antigo do que a Constituição Alemã. Foi desenvolvido primeiramente pelos Tribunais Administrativos Alemães, principalmente o prussiano Oberverwaltungsgericht, no final do século 19, e aplicado em medidas policiais que usurpavam a liberdade ou a propriedade de um indivíduo, nos casos onde a lei dava discricionariedade à polícia, ou regulava atividades policiais de uma forma bastante vaga. ${ }^{12}$ Aqui o princípio da proporcionalidade serviu

9 Stephen Gerald Breyer é um Juiz Associado à parte liberal da Suprema Corte dos Estados Unidos da América, tendo sido indicado na época do então presidente norte-americano Bill Clinton, em 1994.

10 Veja, por exemplo, Turner Broadcasting System, Inc. v. Federal Communication Commission, 520 U.S. 180 (1997); Nixon v. Shrink Missouri Government, 528 U.S. 377 (2000); United States v. Playboy Entertainment Group, Inc., 529 U.S. 803 (2000); Bartnicki v. Vopper, 532 U.S. 514 (2001); Paul Gewirtz, 'Privacy and Speech' (2001) Sup. Ct. Rev. 139.

11 Veja geralmente, David M. Beatty, The Ultimate Rule of Law (Oxford: Oxford University Press, 2005) at 162 [Beatty, The Ultimate Rule of Law]; Donald P. Kommers, The Constitutional Jurisprudence of the Federal Republic of Germany, $2^{\text {nd }}$ ed. (Durham: Duke University Press, 1997) at 46 [Kommers, Constitutional Jurisprudence].

12 Lothar Hirschberg, Der Grundsatz der Verhältnismäßigkeit (Göttingen: Schwarz, 1981) at 6; Barbara Remmert, Verfassungs- und verwaltungsgeschichtliche Grundlagen des Übermaßverbots (Heidelberg: Müller, 1995). 
como um constrangimento adicional sobre a ação da polícia. A ação requeria um objetivo legal. Os meios adotados pela polícia em relação ao cidadão tinham que ser adequados para alcançar o objetivo da lei. Se um meio menos intrusivo para alcançar o fim da lei estivesse disponível, esse meio teria que ser aplicado. Em alguns casos, as cortes perguntavam, além disso, se um equilíbrio adequado entre a ingerência dos meios e a importância do objetivo buscado tinha sido ferido. Um fracasso no cumprimento desses requisitos tornaria ilegais as ações da polícia.

Sob a Lei Fundamental adotada em 1949, a Corte Constitucional, que foi estabelecida em 1951, logo começou a transferir esse teste para a lei constitucional e o aplicou às leis que limitavam direitos fundamentais. Mas, diferentemente do Canadá, a Corte, nas suas primeiras decisões, nem explicava porque a Lei Fundamental requeria limitação de direitos para ser proporcional, nem especificava como o princípio da proporcionalidade operava. Ele foi introduzido como se pudesse ser tido como garantido. ${ }^{13}$ A primeira explicação detalhada sobre o que o princípio exigia e como ele operava foi num caso conhecido que envolvia liberdade de profissão (art. 12). ${ }^{14}$ Aqui o princípio da proporcionalidade apareceu como uma ferramenta que ajudou a enfrentar algumas dificuldades causadas pela linguagem incomum do art. 12. Numa decisão posterior, também envolvendo o art. 12, o teste desenvolvido no 'Pharmacy Case' é descrito como 'o resultado da aplicação estrita do princípio da proporcionalidade [geral] quando o bem comum requer infringimentos da liberdade de profissão'. O modo pelo qual o princípio opera é então explicado em detalhes. ${ }^{15}$

Demorou até 1963 para que a Corte, em um caso envolvendo o direito de integridade física (art. 2 sect. 2), reconhecesse a aplicabilidade do princípio em todos os casos onde as liberdades fundamentais fossem infringidas. ${ }^{16}$ Outros dois anos se passaram antes da Corte explicar onde encontra a base textual para o princípio: 'resulta do princípio do Estado de Direito [garantido no art. 20], ainda mais da própria essência dos direitos fundamentais, que são a expressão da reivindicação geral dos cidadãos à liberdade frente o Estado e que pode ser

13 A primeira decisão que menciona o princípio da proporcionalidade afeta uma lei eleitoral do Estado de Northrhine Westphalia. Ver Entscheidungen des Bundesverfassungsgerichts (hereinafter, BVerfGE), vol. 3, 383 at 399 (1954). Em um caso posterior, a Corte cita uma decisão anterior para apoiar a aplicação do princípio da proporcionalidade. Ver BVerfGE 1, 167, 178 (1952). Contudo, essa decisão simplesmente declara que, mesmo em tempos de limitações emergenciais de direitos, pode não ir além do absolutamente necessário.

14 BVerfGE 7, 377 (1958) [doravante referido como 'Pharmacy Case']. Tradução em inglês (excertos) citados por Kommers, Constitutional Jurisprudence, nota supra 8 at 274 , e em Norman Dorsen et al eds., Comparative Constitutionalism. Cases and Materials (St. Paul: Thomson West, 2003) at 1204 [Dorsen, Comparative Constitutionalism].

15 BVerfGE 13, 97 (1961) at 104. O teste é explicado em 108.

16 BVerfGE 16, 194 at 201 (1963). 
limitada pelo poder público somente enquanto é absolutamente necessário para proteger interesses públicos'. ${ }^{17}$ Nos últimos anos, a proporcionalidade tem sido frequentemente chamada de princípio de lei constitucional. ${ }^{18}$ Uma elaboração sobre qual, precisamente, é a origem da proporcionalidade nunca foi dada, tampouco a Corte elaborou como esse princípio flui do Estado de Direito ou da essência dos direitos fundamentais. ${ }^{19} \mathrm{~A}$ razão para essa taciturnidade pode ser o fato de que na Alemanha, em oposição ao Canadá, nos primeiros anos, a Corte não estava consciente do papel proeminente que a proporcionalidade exerceria no futuro. Quando isso se tornou aparente, o princípio da proporcionalidade já tinha sido estabelecido, de modo que uma argumentação adicional pareceria desnecessária.

Sem tal tentativa de elaboração, o princípio da proporcionalidade parece resultar do texto da Constituição, mais remotamente na Alemanha do que no Canadá. O que aparece como sendo uma interpretação do s. 1 da Charter do Canadá parece ser uma verificação adicional da limitação, a qual suplementa as provisões textuais na Alemanha. A Lei Fundamental Alemã contém apenas umas poucas salvaguardas aplicadas a quaisquer limitações de um direito fundamental, sendo, as mais importantes, a de que toda lei que limita um direito fundamental deve ser uma lei geral (art. 19 sect. 1) e que nenhuma limitação pode afetar a verdadeira essência do direito fundamental (art. 19 sect. 2). Assim, a Lei Fundamental anexa cláusulas especiais de limitação à maioria dos direitos e liberdades da Bill of Rights. ${ }^{20}$ Algumas dessas cláusulas contentam a si mesmas com uma indicação de que as limitações são permitidas somente "pela lei ou de acordo com a lei”, sem acrescentar nenhuma restrição adicional. Isso é verdade para um direito tão importante quanto, por exemplo, o direito à vida e à integridade física (art. 2 sect. 2). Outras cláusulas de limitação têm verificações adicionais quanto à finalidade, às condições ou os meios de limitação. Contudo, não muitas leis são consideradas inconstitucionais porque violam uma cláusula de limitação formal (escrita). Em vez disso, é o princípio de proporcionalidade informal (não escrito) que carrega o peso principal da proteção dos direitos fundamentais na Alemanha.

17 BVerfGE 19, 342 at 348 (1965).

18 Veja, por exemplo, BVerfGE 95, 48 at 58 (1996).

19 O livro precursor é de Peter Lerche, Übermaß und Verfassungsrecht. Zur Bindung des Gesetzgebers an die Grundsätze der Verhältnismäßigkeit und Erforderlichkeit 2nd ed. (Köln: Heymanns, 1999). Veja também Bernhard Schlink, Abwägung im Verfassungsrecht (Berlin: Duncker \& Humblot, 1976). [Schlink, Verhältnismäßigkeit]; Klaus Stern, Zur Entstehung und Ableitung des Übermaßverbots, in: Festschrift für Peter Lerche (München: Beck, 1993) at 165.

20 "Carta ou Lista de Direitos", surgida no Reino Unido, e refere-se à Declaração de Direitos, proposta de lei aprovada pelo Parlamento Britânico em 1689. O documento garante, entre outros direitos, a liberdade, a vida e a propriedade privada, assegurando o poder do Parlamento na Inglaterra. 
Isso não quer dizer que o princípio da proporcionalidade seja uma invenção ilegítima da Corte Constitucional. Se a Corte tivesse tido a necessidade de argumentar que a proporcionalidade decorre da Bill of Rights na Lei Fundamental, não teria encontrado grandes dificuldades. Similar à abordagem intencional do Chief Justice Dickson em Oakes, ${ }^{21}$ a Corte Constitucional poderia ter começado a partir de um realce da importância que foi atribuída aos direitos fundamentais depois do regime nazista e da Segunda Guerra Mundial. De acordo com o art. 1, todos os direitos fundamentais estão alicerçados no princípio da dignidade humana. Ao contrário das constituições prévias alemãs, a Lei Fundamental coloca esses direitos acima da lei e os dota de uma força obrigatória para o Legislativo. No caso Lüth, uma decisão histórica que revolucionou a compreensão dos direitos fundamentais na Alemanha, ${ }^{22}$ a Corte os elevou à categoria dos valores mais altos do sistema legal, os quais não são somente direitos humanos, mas também princípios objetivos. A conclusão tirada dessa premissa foi a de que eles permeiam toda a ordem legal. Eles não estão limitados à aplicação vertical, mas também influenciam as relações da lei privada, tanto quanto funcionam como parâmetros para a interpretação da lei ordinária. A mesma linha de argumento poderia ter levado à conclusão de que isso seria incompatível com a importância atribuída à liberdade individual, que a legislação possa conferir para limitar os direitos fundamentais, até que alcance a última fronteira da sua verdadeira essência.

\section{Diferentes abordagens: 0 objetivo}

Basicamente ambas as jurisdições seguem o mesmo caminho quando aplicam o teste da proporcionalidade. Uma vez que ele requer uma comparação entre meios e fins, ambas as Cortes começam declarando o propósito da lei sob revisão. Apenas um propósito legítimo pode justificar a limitação de um direito fundamental. O teste de proporcionalidade segue três passos. Enquanto a Corte canadense requer uma conexão racional entre o objetivo da lei e os meios empregados pelo Legislativo para atingir sua finalidade na primeira fase, a Corte da Alemanha questiona se a lei é apropriada para alcançar o seu fim na segunda fase. Na segunda fase, a Corte canadense pergunta se, no encalço do seu fim,

21 Oakes, nota supra 2 em para 28.

22 BVerfGE 7, 198 (1958). Traduções em inglês em: Decisions of the Bundesverfassungsgericht, vol. 2, part. I (Baden-Baden: Nomos 1998) at 1; Kommers, Constitutional Jurisprudence, supra note 8 at 361 (excerpts); Vicki C. Jackson and Mark Tushnet (eds.), Comparative Constitutional Law (New York: Foundation, 1999) [Jackson and Tushnet, Comparative Constitutional Law] at 1403 (excerpts); Dorsen, Comparative Constitutionalism, nota supra 11 em 824. 
a lei minimamente prejudica o direito fundamental, enquanto que a Corte alemã questiona se a lei é necessária para alcançar a sua finalidade, ou se existe um meio menos intrusivo que igualmente alcance esse fim. A terceira fase é, em ambos os países, uma análise de custo-benefício, que requer um sopesamento entre os interesses dos direitos fundamentais e o benefício cujo interesse o direito é limitado. Na Alemanha ele é chamado principalmente de proporcionalidade em sentido estrito, mas também adequação, razoabilidade (Zumutbarkeit), etc. ${ }^{23}$

Onde as duas jurisdições diferem? A primeira diferença aparece quando a questão preliminar - que é o objetivo da lei que limita um direito fundamental - é colocada. Enquanto a Suprema Corte do Canadá, no caso Oakes, requer um propósito de 'importância suficiente para garantir a predominância do direito de propriedade protegido constitucionalmente' ou uma preocupação 'urgente e substancial', ${ }^{24}$ a Corte Constitucional da Alemanha requer um 'propósito legitimo'. Por 'legítimo' a Corte entende um propósito não proibido pela Constituição. Nenhum elemento adicional, como uma 'importância suficiente' ou 'necessidade urgente', é requerido. Uma certeza sobre o propósito da lei é indispensável a fim de realizar a análise dos 'meios e fins' durante os passos seguintes do teste de proporcionalidade. Mas a verificação do propósito não faz parte do teste de proporcionalidade. Serve antes como base e ponto de partida. Verificar se um objetivo escolhido pela legislação é suficientemente importante para justificar um certo infringimento de um direito fundamental é de trâmite crucial também para a Corte alemã. Mas isso aparece num estágio posterior do teste, nomeadamente na fase 3 , onde a Corte questiona se um equilíbrio justo entre os interesses concorrentes é ferido. Como resultado, quase nenhuma lei falha nesse estágio. Casos onde a legislação segue um propósito proibido constitucionalmente, como, por exemplo, discriminação racial, são extremamente raros.

A Corte não oferece uma explicação para a limitada compreensão do propósito dentro da estrutura do teste de proporcionalidade. Mas podem-se inferir duas considerações decorrentes desse raciocínio. Primeiro, a Corte sustenta que, em uma democracia, o Legislativo é autorizado a buscar qualquer propósito, desde que não seja excluído pela Constituição. A importância do propósito não é uma condição para a ação legislativa. O que é suficientemente importante para se tornar um objeto de legislação é uma questão política, e tem que ser determinada num processo democrático. Em segundo lugar, a importância é considerada como uma noção correlacional que não pode ser determinada em termos abstratos.

23 Bons exemplos do funcionamento do teste são, por exemplo, BVerfGE 81, 156 at 188 (1990); BVerfGE 90, 145 (1994); BVerfGE 91, 207 at 222 (1994).

24 R. v. Big M Drug Mart Ltd., [1985] 1 S.C.R. 295 a 352. 
Consequentemente, a questão de saber se o objetivo é suficientemente importante para justificar certas limitações de um direito pode encontrar sua resposta somente nas fases seguintes do teste da proporcionalidade. Levantar essa questão, em conexão com o propósito, poderia ser considerado como uma antecipação prematura do equilíbrio final. Contudo, a diferença parece desaparecer na prática. É bastante instrutivo ver que quase nenhuma lei canadense falha por causa de um propósito insuficiente. Como na Alemanha, uma lei é considerada inconstitucional no Canadá se o seu propósito é incompatível com a Constituição. ${ }^{25}$ Mas qualquer propósito legal é considerado um propósito suficiente.

A determinação do propósito de uma lei não tem sido uma parte particularmente difícil da aplicação do princípio da proporcionalidade na Alemanha. Geralmente a história legislativa contém informação suficiente sobre o seu propósito. Dificuldades podem surgir com compromissos de última hora no Legislativo, especialmente no Comitê de Conciliação das duas Casas do Parlamento, quando os propósitos são adotados no plenário, sem debate. Mas a impossibilidade de se descobrir o que o Legislativo tinha em mente quando promulgou uma certa lei é uma rara exceção. ${ }^{26}$ Isso não quer dizer que esse estágio é de pequena importância. A distinção entre meios e fins pode ser bem difícil. Numa perspectiva mais ampla, um fim estritamente definido pode parecer um meio para um propósito mais abstrato. Ele desempenha um papel proeminente, contudo, quando se trata de determinar valores ou interesses divergentes no processo de sopesamento da fase 3 .

Na fase 1, a diferença entre os dois países parece ser meramente semântica e não muitas leis falham nesse nível. ${ }^{27}$ Sua função é eliminar o pequeno número de casos de fuga. Do mesmo modo, a fase 2 parece diferir apenas na terminologia entre as duas jurisdições. 'Necessário' alcançar o objetivo da lei quer dizer, na jurisprudência constitucional alemã, que meios menos intrusivos não estão disponíveis. Isso é apenas uma formulação diferente para 'prejuízo mínimo'. Vice-versa, na descrição do 'prejuízo mínimo', os autores canadenses frequentemente usam o termo 'necessário'. ${ }^{28} \mathrm{~A}$ informação sobre os meios menos intrusivos é usualmente estabelecida pela parte que desafia a lei no seu fundamento. Contudo, é interessante observar que no Canadá a maioria das leis que são consideradas

25 Veja, Joel Bakan et al eds., Canadian Constitutional Law, 3rd ed. (Toronto: Emond Montgomery, 2003) at 759 [Bakan, Canadian Constitutional Law].

26 Como exemplo, veja BVerfGE 9, 291 (1959). Da mesma forma, o problema de propósitos inconstantes não tem surgido na Alemanha.

27 Um bom exemplo de um meio impróprio era uma lei de caça que exigia um teste de arma de fogo para falcoeiros. No entanto, falcoaria não é caçar falcões com uma arma, mas caçar outros animais de caça com um falcão. Veja BVerfGE 55, 159 (1980).

28 Veja, por exemplo, Bakan, Canadian Constitutional Law, nota supra 21 at 760. 
inconstitucionais falha nessa etapa. Na Alemanha, a porcentagem das leis que falham na fase 2 é consideravelmente maior do que as leis que falham na fase 1. Mas não é nem de longe tão grande quanto a porcentagem no Canadá. A vasta maioria das leis que não passam no teste da proporcionalidade na Alemanha o fazem na fase 3 .

\section{Mais diferenças: fase 2}

Aqui estão algumas características que podem explicar por que a fase 2 ganhou menos importância na Alemanha do que no Canadá. Primeiramente, a importância do objetivo da lei não desempenha um papel nesse estágio. O objetivo é aceito como legal e a única questão é se esse objetivo poderia ter sido alcançado efetivamente por meios mais brandos. Em segundo lugar, a Corte Constitucional não requer que os meios escolhidos pelo Legislativo alcancem completamente o objetivo da lei. Uma contribuição, até a mais modesta, é suficiente, contanto que a mesma contribuição não possa ser alcançada pelos meios que prejudicam menos o direito fundamental. A comparação entre os efeitos deletérios e saudáveis da lei impugnada requerida pelo aperfeiçoado teste Oakes não é realizada na fase 2 na Alemanha. Em terceiro lugar, a violação consiste em um encargo financeiro imposto ao cidadão (que é o caso, muito frequente, de várias leis reguladoras da economia e que afetam a liberdade de profissão ou propriedade), um meio menos intrusivo pode sempre ser encontrado: alguém mais paga ou o Estado aloca dinheiro do seu orçamento. Consequentemente, nesses casos, o teste não exclui nada. A questão, portanto, se torna uma das adequações da medida a ser decidida na fase $3 .^{29}$

Além disso, a Corte da Alemanha nunca impôs elevado ônus da prova ao governo, como a Suprema Corte Canadense fez em Oakes, quando pediu evidência 'convincente e persuasiva' em conexão com os 'elementos constituintes de um inquérito s. 1'. ${ }^{30}$ Se é verdade que Oakes criou um 'enorme dilema institucional' para a Corte, ao negligenciar a realidade da política feita em condições de incerteza, ${ }^{31}$ a Corte alemã evitou esse dilema, visto que sempre enfatizou que o Legislativo gozasse de um certo grau de discrição política para escolher os meios de alcançar um objetivo legislativo. ${ }^{32}$ Isso reflete a realidade da política de tomada de decisão. Geralmente, não é difícil demais verificar se há meios menos intrusivos. É mais difícil, contudo, descobrir se teriam o mesmo ou um efeito equivalente.

29 Veja BVerfGE 77, 308 a 334 (1987).

30 Oakes, nota supra 2 em para 68.

31 Choudhry, 'So What is the Real Legacy of Oakes?' nota supra 4, em 503, 524.

32 Veja, por exemplo, BVerfGE 30, 250 at 263 (1971). 
Isso é particularmente verdadeiro quando, na determinação da questão de se os meios irão contribuir para alcançar o fim, a resposta dependa dos prognósticos. o processo principal é o caso Kalkar, o qual envolveu os riscos das centrais de energia atômica. ${ }^{33} \mathrm{Na}$ ausência de evidência sobre uma nova tecnologia atômica, a Corte recusou-se a substituir opiniões judiciais por opiniões políticas, mas combinou essa deferência com um dever constitucional do Legislativo para observar o desenvolvimento e, se necessário, emendar a lei. No Codetermination Case, a Corte esclareceu sua posição. ${ }^{34}$ Por um lado, incerteza sobre futuros desenvolvimentos, mesmo em questões de grande impacto, não pode ser justificada como proibição de legislar. Por outro lado, só a incerteza não pode apenas justificar um domínio político isento de controle judicial. A Corte então desenvolve uma escala de análise minuciosa que alcança desde: se o prognóstico do Legislativo está evidentemente errado ("Evidenzkontrolle”), passando para um teste de razoabilidade ("Vertretbarkeitskontrolle”), até um exame minucioso estrito ("intensivierte inhaltliche Kontrolle"), dependendo da natureza da área política, da possibilidade para basear a decisão sobre fatos confiáveis e da importância de bens ou interesses, constitucionalmente protegidos, em jogo. A Corte não hesita em coletar fatos por si mesma, se necessário. ${ }^{35}$

O rigor de Oakes pode talvez ser explicado pelo pressuposto do Chief Justice Dickson, de que os direitos e liberdades garantidos pela Charter não são absolutos, mas que limites sobre eles são 'exceção' e podem ser justificados somente por 'critérios excepcionais'. ${ }^{36}$ Seria difícil encontrar uma linguagem similar na jurisprudência da Corte alemã. Desde o início, as limitações de direitos fundamentais foram consideradas normais, porque todos os direitos e liberdades podem colidir ou podem ser usurpados. A harmonização dos direitos em conflito e a prevenção de abusos de liberdade são tarefas normais do Legislativo. A função das garantias constitucionais de direitos não é fazer limitações tão difíceis quanto possíveis, mas requerer justificações especiais para as limitações que as faça compatíveis

33 BVerfGE 49, 89 at 130 (1978). Tradução em inglês (excertos) citado de Kommers, Constitutional Jurisprudence, nota supra 8 a 139; Dorsen, Comparative Constitutionalism, nota supra 11 a 239.

34 BVerfGE 50, 290 a 331 (1979) [a seguir 'Codetermination Case']). Tradução em inglês (excertos) citado de Kommers, Constitutional Jurisprudence nota supra 8 a 267. Para casos de igualdade comprar BVerfGE 88,87 a 96 (1993).

35 Veja Klaus Jürgen Philippi, Tatsachenfeststellungen des Bundesverfassungsgerichts (Köln: Heymanns, 1971); Brun-Otto Bryde, Tatsachenfeststellungen und soziale Wirklichkeit in der Rechtsprechung des Bundesverfassungsgerichts, in: Festschrift 50 Jahre Bundesverfassungsgericht, vol. I (Tübingen: Mohr Siebeck, 2001) at 533. Em casos de revisão judicial de legislação, a Corte geralmente solicita declarações de agências ou escritórios, como o Bureau de Estatística e de instituições interessadas ou informadas, ou grupos sociais. Às partes de um processo é dada a oportunidade de expressar sua opinião sobre essas declarações. Em alguns casos, a Corte ouve peritos, que ela seleciona de forma independente das partes no processo.

36 Oakes, nota supra 2 em para 65. 
com o princípio geral da autonomia individual e da dignidade. Algumas limitações posteriores ao teste de Oakes parecem levar isso em consideração. ${ }^{37}$

Em Edwards Books, a Corte canadense menciona pela primeira vez que proteger um 'vulnerável' ou 'não... poderoso grupo da sociedade' pode justificar uma limitação em face daqueles que lucram com essa vulnerabilidade. A Corte acrescenta, contudo, que a legislação não é constitucionalmente obrigada a oferecer proteção, "mas ela pode fazer isso, se quiser". ${ }^{38}$ A Corte Constitucional alemã foi além nessa direção. Começando em 1975, reconheceu como um dever constitucional proteger direitos fundamentais, não somente em face do Estado, mas também em face das ameaças decorrentes de grupos privados ou forças sociais. ${ }^{39}$ Uma vez que ameaças desse tipo são um resultado do exercício de direitos fundamentais, o dever só pode ser cumprido pela limitação dos direitos de um grupo para proteger os direitos de outro grupo. Consequentemente, a lei não pode apenas violar a Constituição quando ela vai longe demais na limitação de um direito fundamental (“Übermaßverbot”), mas também quando faz muito pouco para proteger um direito fundamental ("Untermaßverbot”). ${ }^{40}$

Um caso especial é a legislação do direito privado. Ao contrário da legislação do direito público, a legislação do direito privado diz respeito à relação entre os indivíduos, em oposição à relação entre o indivíduo e o Estado. Considerando os direitos fundamentais, as relações do direito público são assimétricas: apenas os indivíduos têm direitos fundamentais, enquanto que o Estado está vinculado a esses direitos. A legislação do direito privado, portanto, frequentemente vai exigir uma conciliação de dois interesses privados competitivos, ambos protegidos por direitos fundamentais. Isso significa que a proteção do direito ameaçado pode ser assegurada somente pela limitação de outros direitos constitucionalmente protegidos. Em tal situação, a questão apresentada na fase 2, de saber se a limitação de um direito fundamental foi longe demais, não pode ser respondida sem se perguntar se a proteção dada ao direito ameaçado foi suficiente. A Corte canadense aparentemente resolve esse problema reduzindo os padrões de escrutínio

37 Comparar Edwards Books and Art Ltd. v. The Queen, [1986] 2 S.C.R. 713 [Edwards Books]; Irwin Toy Ltd. v. Quebec, [1989] 1 S.C.R. 927; RJR MacDonald Inc. v. Canada, [1995] 3 S.C.R. 199.

38 Edwards Books, ibid.

39 BVerfGE 39,1 a 42 (1975). Tradução em inglês (excertos) em Kommers, Constitutional Jurisprudence, supra note 8 at 336; Jackson and Tushnet, Comparative Constitutional Law, nota supra 18 a 115; Dorsen, Comparative Constitutionalism, nota supra 11 a 542. Veja Dieter Grimm, 'The Protective Function of the State' in Georg Nolte (ed.), European and US Constitutionalism (Cambridge: Cambridge U.P., 2005) 137; Dieter Grimm, 'Human Rights and Judicial Review in Germany' in: David M. Beatty (ed.), Human Rights and Judicial Review (Dordrecht: Nijhoff, 1994) 267 at 279 [Beatty, Human Rights]; Beatty, The Ultimate Rule of Law, nota supra 8 a 145

40 BVerfGE 88, 203 a 254 (1993). Tradução em inglês (excertos) em Kommers, Constitutional Jurisprudence, nota supra 8 a 349; Jackson and Tushnet, Comparative Constitutional Law, nota supra 18 a 134. 
(fiscalização) a um dano mínimo. A Corte alemã achou que, aqui, a relação entre meios e fins não está mais em jogo. Portanto, a fase 2 não fornece uma resposta para a Corte resolver esse problema na fase 3.

\section{Uma grande lacuna: equilíbrio}

A diferença mais impressionante entre a duas jurisprudências é a alta relevância da fase 3 do teste da proporcionalidade na Alemanha e a sua função residual no Canadá. Aqui, a Corte alemã argumenta longamente, enquanto a Corte canadense apresenta sobretudo um 'currículo de análise prévia'. ${ }^{41}$ Como essa diferença pode ser explicada? A análise a ser feita na fase 3 é descrita diferentemente em ambas as jurisdições. Como é colocado pelo Chief Justice Dickson em Oakes, o passo final requer "proporcionalidade entre os efeitos das medidas que são responsáveis pela limitação do direito da Charter ou de liberdade, e o objetivo que é identificado como 'importância (relevância) suficiente'”. ${ }^{42} \mathrm{Na}$ sua forma aperfeiçoada em Dagenais, o teste requer 'que o objetivo subjacente da medida e os efeitos salutares que realmente resultam da sua implementação sejam proporcionais aos efeitos deletérios que a medida tem sobre direitos e liberdades' ${ }^{43}$ A Corte alemã pesa a gravidade da infração contra a importância e urgência dos fatores que a justificam. Em outras palavras, a Corte compara a perda do direito violado, se a lei for mantida, com a perda do valor protegido pela lei, se o direito fundamental prevalecer.

Essa comparação difere da avaliação feita nas fases 1 e 2 do teste de proporcionalidade. Essas fases são limitadas a um exame rigoroso de meios e fins. A ideia é de que esses meios legislativos, que não são necessários para alcançar os objetivos da lei, não possam justificar a limitação de direitos fundamentais. $\mathrm{Na}$ fase 3, a Corte deixa a análise de meios e fins das fases 1 e 2 para trás. Aqui, o objeto de comparação muda e o escopo da análise se amplia. A comparação agora é entre a perda de um direito fundamental, por um lado, e o ganho de um bem protegido pela lei, por outro lado, o qual, por si mesmo, frequentemente gozará de reconhecimento constitucional. Esse equilíbrio não é abstrato. A Corte Constitucional não reconhece uma hierarquia entre vários direitos constitucionais.

41 Frank lacobucci, 'Judicial Review by the Supreme Court of Canada under the Canadian Charter of Rights and Freedoms: The First Ten Years' in Beatty, Human Rights, nota supra 35 a 121.

42 Oakes, nota supra 2 a para 70.

43 Dagenais v. Canadian Broadcasting Corporation, [1994] 3 S.C.R. 835 at 887. Para um caso similar na Alemanha ver BVerfGE 35, 202 (1973). Tradução em inglês (excertos) em Kommers, Constitutional Jurisprudence, nota supra 8 a 416; Basil S. Markesinis, The German Law of Torts: A Comparative Introduction, 3rd ed. (Clarendon: Oxford University Press, 1997) na 390. 
O equilíbrio, portanto, tem que ser concreto ou, na terminologia canadense, contextual. Uma questão é o quanto intensivamente o direito é infringido. Outra questão é o quanto é sério o perigo para o bem protegido pela lei, e o quanto é provável que esse perigo se materialize. Além disso, o grau da contribuição, efetuado pela lei impugnada para proteger o bem contra o perigo, tem que ser medido em contraste com o grau de intrusão.

Contudo, esse conceito não é, de forma alguma, estranho à Corte canadense. Já em Oakes, o Chief Justice Dickson admite que a proteção integral dos direitos fundamentais é impossível sem a fase 3. 'Mesmo que um objetivo seja de importância suficiente, e o primeiro de dois elementos do teste de proporcionalidade seja satisfeito, ainda é possível que, pela severidade dos efeitos deletérios da medida sobre indivíduos ou grupos, a medida não seja justificada pelos propósitos que ela pretende servir'. ${ }^{44}$ A semelhança da abordagem alemã se torna ainda mais clara em Thomson Newspapers Co. v. Canada (Attorney General), ${ }^{45}$ onde a Corte declara que a fase 3 do teste de proporcionalidade desempenha um papel fundamentalmente distinto comparado aos passos anteriores:

O foco da primeira e da segunda fase da análise de proporcionalidade não é a relação entre as medidas e o direito Charter em questão, mas antes a relação entre os fins da legislação e os meios empregados. 0 terceiro estágio da análise da proporcionalidade fornece uma oportunidade de avaliar se os benefícios da limitação acrescentados são proporcionais aos seus efeitos deletérios, como foram medidos pelos valores fundamentais subjacentes em [Charter].

A explicação para essa brecha, entre o argumento da Corte e sua prática, deve ser buscada no fato de que os elementos relevantes da fase 3 já foram tratados nas fases anteriores. A importância do objetivo tem sido geralmente determinada nos passos preliminares, onde a Corte não somente verifica o propósito da lei, mas questiona, além disso, se ela é suficientemente 'urgente e substancial' para justificar a limitação dos direitos da Charter. Os efeitos do infringimento sobre os beneficiários da proteção são considerados em conexão com a existência de uma violação, e nas duas fases anteriores do teste, para que não reste muito a ser dito quando a Corte alcançar a fase 3. Consequentemente, a fonte das limitações inconstitucionais tem sido sempre encontrada nos estágios anteriores.

44 Oakes, nota supra 2 a para 71.

45 [1998] 1 S.C.R. 877 [Thomson]. 
O observador alheio tem a impressão de que a Suprema Corte canadense evita a fase 3 pelo temor de que sejam tomadas decisões políticas nesse estágio, em vez de decisões legais. Estudiosos constitucionais apoiam a Corte nessa atitude. ${ }^{46}$ Contudo, na prática, o trato dessa Corte na fase 2 parece muito mais carregado de valor do que no tratamento da fase 2 pela Corte alemã. Tome-se como exemplo as longas considerações do Chief Justice Dickson em Keegstra, ou os comentários da então Justice McLachlin ${ }^{47}$ na sua opinião divergente. ${ }^{48}$ Eles contêm muito mais do que seria necessário para responder à questão posta na fase 2, a saber: se há meios alternativos que alcancem o objetivo da lei tão efetivamente quanto os meios escolhidos pela legislação, mas imponham um fardo menor sobre o direito limitado pela lei. o mesmo é verdadeiro para o tipo e a dimensão do perigo que a lei quer remediar. É revelador que, às vezes, a Corte use a expressão que, em vista de um dado perigo, a lei não 'restrinja excessivamente' a garantia, um tipo de linguagem que é típica do processo de equilíbrio reservado para o estágio 3 na Alemanha.

Se realmente a tentativa de evitar considerações políticas e valorizar julgamentos é responsável pela relutância em entrar na fase 3, a Corte se arrisca a um autoengano, quando todas as considerações orientadas por valores são feitas sob o disfarce de uma aparente categoria imparcial. A questão interessante, portanto, é se o estágio 3, propriamente compreendido, realmente força a Corte a deixar a esfera legal e virar-se para considerações políticas. Temores como esses existem não somente no Canadá. Há críticos também na Alemanha. Bernhard Schlink é talvez o mais proeminente. ${ }^{49}$ Ele admite sopesamento no estágio 3 , quando a Corte Constitucional revisa atos do Executivo e decisões de cortes inferiores. Mas ele quer excluí-la quando atos legislativos estão em jogo. Ele argumenta que equilibrar interesses conflitantes, estabelecer prioridades, alocar recursos, é uma função genuinamente política. Em sua visão, a Corte deixa sua esfera legal e usurpa essa função quando tais interesses se equilibram. Críticos, contudo, são uma pequena minoria na Alemanha, e o sopesamento é constantemente praticado pelo Judiciário.

46 Veja, por exemplo, Peter W. Hogg, 'Section 1 Revisited' (1991) 1 N.J.C.L. 1 a 22.

47 Beverley McLachlin é atual Chefe de Justiça da Suprema Corte do Canadá, a primeira mulher a ocupar essa posição, e a mais antiga Chefe de Justiça na história do Canadá. Em seu papel como presidente da Suprema Corte, ela também atua como deputada do Governador Geral do Canadá.

48 R. v. Keegstra, [1990] 3 S.C.R. 697.

49 B.Schlink, Verhältnismäßigkeit, nota supra 16; B. Schlink, Der Grundsatz der Verhältnismäßigkeit, em: Festschrift 50 Jahre Bundesverfassungsgericht, nota supra 31, vol. II, at 445 . Recente advertência ligeiramente diferente ver Frank Raue, Müssen Grundrechtsbeschränkungen wirklich verhältnismäßig sein' (2006) 131 Archiv des öffentlichen Rechts 79. 


\section{Preocupações justificadas?}

Minha resposta às críticas, de que a fase 3 seja uma política carregada, é dupla. Primeiro, eu sou da opinião de que, sem a fase 3 do teste de proporcionalidade propriamente compreendido, seria impossível se alcançar o seu propósito, nomeadamente dar eficácia plena aos direitos fundamentais. Isso porque o impacto de uma violação de um direito fundamental pode ser amplamente avaliado somente na fase 3. As duas fases anteriores podem revelar a falha da lei ao alcançar seu objetivo. Elas não podem avaliar o peso relativo do objetivo da lei por um lado, e o direito fundamental pelo outro, no contexto da legislação sob revisão. Tome-se o caso hipotético de uma lei que permite à polícia atirar em uma pessoa para matar, se esse for o único meio de impedir um agressor de destruir uma propriedade. Na Alemanha, a propriedade é constitucionalmente garantida. A proteção da propriedade certamente é um propósito legítimo ainda mais importante. Atirar em um agressor para matar é um meio apropriado de impedi-lo de destruir uma propriedade. Desde que atirar seja permitido, somente se outros meios não estiverem disponíveis, a necessidade do teste na fase 2 é também aprovada. Se tivesse que parar aqui, o equilíbrio entre a vida e a propriedade poderia não ser feito. A lei poderia ser considerada constitucional e a vida poderia não obter a proteção que ela merece.

Em segundo lugar, na minha visão, o perigo de decisões políticas pode ser evitado por uma determinação cuidadosa sobre o que é colocado dentro de duas escalas quando se chega ao sopesamento. Isso é raramente o caso de uma medida legal afetar um direito fundamental completamente. Geralmente, somente um certo aspecto de um direito é considerado. Por exemplo, uma lei pode não regular todo o discurso, mas preferivelmente um discurso comercial relativo a certos produtos em uma certa mídia. 0 peso do aspecto de um direito, o qual é regulado em relação ao direito em geral, deve ser determinado cuidadosamente. O mesmo é verdadeiro para o bem cujo interesse está restrito. Raramente é uma medida apta para dar proteção completa a certo bem. Somente certos aspectos desse bem serão afetados de um modo salutar. A importância desses aspectos, na visão de um bem em geral, tem que ser cuidadosamente determinada, bem como o grau de proteção que essa medida renderá. ${ }^{50}$ Se isso for feito com precisão, o processo de equilíbrio permanece suficientemente conectado à lei e deixa espaço suficiente para uma escolha legislativa.

50 No mesmo sentido Edmonton Journal v. Alberta, [1989] 2 S.C.R. 1326: 'Uma coisa parece clara e isso é que não se deve equilibrar um valor em geral e o valor conflitante no seu contexto. Para isso poderia muito bem ser um pré-julgamento da questão'. A Corte Constitucional alemã nem sempre evitou esse perigo. 
Assim, permanece uma questão final a ser interrogada. Importa que a Suprema Corte do Canadá, considerando que a minha análise de sua jurisprudência seja correta, faça menos do que ela promete na fase preliminar do princípio da proporcionalidade, faça mais do que ela promete na fase 2 , e tenha pouco uso para a fase 3 ? Isso indica uma imprecisão quando uma fase de um teste de três fases (com uma preliminar) consiste em uma repetição de resultados de estágios anteriores? Em outras palavras, é suficiente que as questões relevantes sejam perguntadas em algum lugar, ou há um valor legal em aumentá-las em uma certa medida? A resposta definitiva requereria um maior conhecimento da jurisprudência da Corte, mais profundo do que eu tenho. O que eu posso concluir é que o efeito disciplinador e racionalizador, o qual é uma grande vantagem do teste de proporcionalidade, comparado a um mero teste de razoabilidade, um balanço mais ou menos livre como em muitos casos dos EUA, é reduzido quando os quatro estágios não são separados claramente. Cada fase requer uma certa avaliação. A próxima fase pode somente ser tomada se a lei que é desafiada não falhar na fase anterior. Uma confusão de fases cria o perigo que elementos entrem em operação de um modo incontrolável e rendam um resultado mais arbitrário e menos previsível.

\begin{abstract}
The German Constitutional Court (1951) began to transfer the proportionality test for constitutional law and applied the laws that limit fundamental rights. The principle of proportionality is apparent from the text of the Constitution, more remotely in Germany than in Canada. Basically both jurisdictions follow the same path when applying the test of proportionality. Since it requires a comparison between means and ends, both Courts begin by stating the purpose of the law under review. The third phase of the test is, in both countries, a cost-benefit analysis, which requires a balancing between the interests for fundamental rights and the benefit of the right whose interest is limited. Phase 3 of the proportionality test gives full effect to fundamental rights. The first two phases can reveal the failure of the law to reach your goal. The danger of political decisions can be avoided by determining carefully about what is valued when it comes to balancing. Each phase requires a certain evaluation, and the next phase can be assessed only if the law is challenged not fail in the previous phase. Confusion phases, which can generate an arbitrary and less predictable outcome, should be avoided.
\end{abstract}

Keywords: Proporcionality. Test. Jurisprudence. Canadian. Germany.

Contents: 1 Oakes and the German model - 2 Development of proportionality in Germany - $\mathbf{3}$ Different approaches: the objective $-\mathbf{4}$ More diferences: step $2-5$ A wide gap: balancing $-\mathbf{6}$ Justified concerns? - References

\title{
Referências
}

Bakan, Canadian Constitutional Law, supra note 21 at 760 .

Bartnicki v. Vopper, 532 U.S. 514 (2001). 
Barbara Remmert, Verfassungs- und verwaltungsgeschichtliche Grundlagen des Übermaßverbots (Heidelberg: Müller, 1995).

Basil S. Markesinis, The German Law of Torts: A Comparative Introduction, 3rd ed. (Clarendon: Oxford University Press, 1997) at 390.

Bernhard Schlink, Abwägung im Verfassungsrecht (Berlin: Duncker \& Humblot, 1976) [Schlink, Verhältnismäßigkeit].

B. Schlink, Verhältnismäßigkeit, B. Schlink, Der Grundsatz der Verhältnismäßigkeit, in: Festschrift 50 Jahre Bundesverfassungsgericht, vol. II, at 445.

BVerfGE 35, 202 (1973).

BVerfGE 1, 167, 178 (1952).

BVerfGE 7, 377 (1958) [hereinafter referred to as the 'Pharmacy Case'].

BVerfGE 13, 97 (1961) at 104, 108.

BVerfGE 16, 194 at 201 (1963).

BVerfGE 19, 342 at 348 (1965).

BVerfGE 95, 48 at 58 (1996).

BVerfGE 7, 198 (1958).

BVerfGE 9, 291 (1959).

BVerfGE 55, 159 (1980).

BVerfGE 77, 308 at 334 (1987).

BVerfGE 30, 250 at 263 (1971).

BVerfGE 49, 89 at 130 (1978).

BVerfGE 50, 290 at 331 (1979) [hereinafter the 'Codetermination Case'].

BVerfGE 88, 87 at 96 (1993).

BVerfGE 81, 156 at 188 (1990).

BVerfGE 90, 145 (1994).

BVerfGE 91, 207 at 222 (1994).

BVerfGE 88, 203 at 254 (1993). English translation (excerpts) in Kommers, Constitutional Jurisprudence, supra note 8 at 349 .

BVerfGE 39,1 at 42 (1975). English translation (excerpts) in Kommers, Constitutional Jurisprudence, supra note 8 at 336 .

Brun-Otto Bryde, Tatsachenfeststellungen und soziale Wirklichkeit in der Rechtsprechung des Bundesverfassungsgerichts, in: Festschrift 50 Jahre Bundesverfassungsgericht, vol. I (Tübingen: Mohr Siebeck, 2001) at 533.

Canadian Charter of Rights and Freedoms, Part I of the Constitution Act, 1982, being Schedule B to the Canada Act 1982 (U.K.), 1982, c.11 [Charter]. 
Gas \& Electric Corp. v. Public Service Commission of New York. 447 U.S. 557 (1980) [Central Hudson].

Dagenais v. Canadian Broadcasting Corporation, [1994] 3 S.C.R. 835 at 887.

David M. Beatty, The Ultimate Rule of Law (Oxford: Oxford University Press, 2005) at 162 [Beatty, The Ultimate Rule of Law]

Decisions of the Bundesverfassungsgericht, vol. 2, part. I (Baden-Baden: Nomos 1998) at 1.

Delisle v. Canada, [1999] 2 S.C.R. 989; Figueroa v. Canada (Attorney General), [2003] 1 S.C.R. 912.

Dieter Grimm, 'The Protective Function of the State' in Georg Nolte (ed.), European and US Constitutionalism (Cambridge: Cambridge U.P., 2005) 137.

Dieter Grimm, 'Human Rights and Judicial Review in Germany' in: David M. Beatty (ed.), Human Rights and Judicial Review (Dordrecht: Nijhoff, 1994) 267 at 279 [Beatty, Human Rights].

Donald P. Kommers, The Constitutional Jurisprudence of the Federal Republic of Germany, $2^{\text {nd }}$ ed. (Durham: Duke University Press, 1997) at 46 [Kommers, Constitutional Jurisprudence].

Dorsen, Comparative Constitutionalism, Cases and Materials (St. Paul: Thomson West, 2003)

Edmonton Journal v. Alberta, [1989] 2 S.C.R. 1326

Edwards Books and Art Ltd. v. The Queen, [1986] 2 S.C.R. 713 [Edwards Books].

Entscheidungen des Bundesverfassungsgerichts (hereinafter, BVerfGE), vol. 3, 383 at 399 (1954).

Frank lacobucci, 'Judicial Review by the Supreme Court of Canada under the Canadian Charter of Rights and Freedoms: The First Ten Years' in Beatty, Human Rights, 35 at 121.

Frank Raue, Müssen Grundrechtsbeschränkungen wirklich verhältnismäßig sein' (2006) 131 Archiv des öffentlichen Rechts 79.

Irwin Toy Ltd. v. Quebec, [1989] 1 S.C.R. 927.

Jackson and Mark Tushnet (eds.), Comparative Constitutional Law (New York: Foundation, 1999) [Jackson and Tushnet, Comparative Constitutional Law] at 1403 (excerpts);

Joel Bakan et al eds., Canadian Constitutional Law, 3rd ed. (Toronto: Emond Montgomery, 2003) at 759 [Bakan, Canadian Constitutional Law].

Klaus Stern, Zur Entstehung und Ableitung des Übermaßverbots, in: Festschrift für Peter Lerche (München: Beck, 1993) at 165.

Klaus Jürgen Philippi, Tatsachenfeststellungen des Bundesverfassungsgerichts (KöIn: Heymanns, 1971).

Kommers, Constitutional Jurisprudence, supra note 8 at 274 and in Norman Dorsen et al eds.

Lorraine Weinrib, 'Canada's Charter of Rights: Paradigm Lost?' (2002) 6 Rev. Const. Stud. 119 [Weinrib, 'Paradigm Lost?'].

Lothar Hirschberg, Der Grundsatz der Verhältnismäßigkeit (Göttingen: Schwarz, 1981) at 6.

Nixon v. Shrink Missouri Government, 528 U.S. 377 (2000). 
Paul Gewirtz, ‘Privacy and Speech’ (2001) Sup. Ct. Rev. 139.

Peter W. Hogg, 'Section 1 Revisited’ (1991) 1 N.J.C.L. 1 at 22.

Peter Lerche, Übermaß und Verfassungsrecht. Zur Bindung des Gesetzgebers an die Grundsätze der Verhältnismäßigkeit und Erforderlichkeit 2nd ed. (Köln: Heymanns, 1999).

RJR MacDonald Inc. v. Canada, [1995] 3 S.C.R. 199 at paras. 179-192.

R. v. Oakes [1986] 1 S.C.R.103 [Oakes].

R. v. Big M Drug Mart Ltd., [1985] 1 S.C.R. 295 at 352.

RJR MacDonald Inc. v. Canada, [1995] 3 S.C.R. 199.

R. v. Keegstra, [1990] 3 S.C.R. 697

Sujit Choudhry, 'So What Is the Real Legacy of Oakes? Two decades of Proportionality Analysis under the Canadian Charter's Section 1' (2006) 34 Sup. Ct. L. Rev. (2d) 501 [Choudhry, 'So What is the Real Legacy of Oakes?'].

Thomson Newspapers Co. v. Canada (Attorney General) [1998] 1 S.C.R. 877 [Thomson].

Turner Broadcasting System, Inc. v. Federal Communication Commission, 520 U.S. 180 (1997).

United States v. Playboy Entertainment Group, Inc., 529 U.S. 803 (2000).

Vicki C. Jackson and Mark Tushnet (eds.), Comparative Constitutional Law (New York: Foundation, 1999) [Jackson and Tushnet, Comparative Constitutional Law] at 1403 (excerpts).

Vriend v. Alberta, [1998] 1 S.C.R. 493 at paras.108-end; M. v. H., [1999] 2 S.C.R. 3 at paras. 75 -end.

Recebido em: 21.10.2015

Aprovado em: 12.07.2016

Informação bibliográfica deste texto, conforme a NBR 6023:2002 da Associação Brasileira de Normas Técnicas (ABNT):

GRIMM, Dieter. Proporcionalidade na jurisprudência constitucional canadense e germânica. Direitos Fundamentais \& Justiça, Belo Horizonte, ano 10, n. 34, p. 69-87, jan./jun. 2016. 